\title{
Publish or Perish: Digital Presence and Mobility as Worth
}

\author{
Rick Dolphijn
}

\section{Introduction}

The erosion of geography and the compression and convergence of time, place and space have been emphatically reasoned and documented in the century of the digital diaspora. Humanity connects, embeds and transports across dimensionality and context. New media, most notably the Internet and mobile devices, have re-arranged our sense(s) of private and public, work and play, social and self, in profound and unexpected ways (Licoppe 2004; Ito et al. 2005; Arminen and Weilenmann 2009). The "technologies and practices of networked mobility" (Wilken 2009: 2) have become a defining quality of modern life, offering advantages of utility and status. To meet these expectations, technologies are shaping our notions of social worth, citizenship and self-esteem. Our capacity to operate as a social broadcaster and sensor in a networked culture is prized and fettishized. Burgleman tells us that the 'myth' of communication "has even replaced 'progress' as the dominant paradigm of capitalist discourse" (Burgelman 2000: 6). Is it true that power and influence can come from almost anywhere in our new age of democratised media, but they require presence to be heard and proliferation to impact. The intersect of acceleration and mobility problematises temporal abstentions, with rhetoric of transformative speed and movement promoting a cultural devaluation of prolonged repose. Those who lack the resources, literacies or will to perform the role of transmitter are resigned to a discrete spatial and temporal territory - they are invisible and less 'effective'. This paper ponders the question: what happens to those who are not creating and socialising media, reaffirming our existence and value via tribal, commercial and commentative lenses? Does an unpublished self perish?

Amelia Potter offered us the term 'zones of silence' in 2006 as a less binary descriptor for the digital divide. As Potter explains: "Zones of silence exist within countries with little connectivity altogether, as well as within zones of high connectivity. They are the places, communities, and homes in the developed/developing worlds where — because of a lack of access to ICTs - people's voices are, effectively, outside of their immediate community, unconnected and unheard." (Potter 2006). Sherry Turkle tells us in her Alone Together thesis: "People are lonely. The network is seductive. But if we are always on, we may deny ourselves the rewards of solitude" (Turkle 2010: 3). Potter highlights the problem of being off: one can be discounted altogether. Turkle highlights the challenge of being on: distractibility and exhaustion. Humanity, of course, sits astride these antinomical poles. We must work then, as Potter suggests, to combat enforced zones of silence while protecting the right to be silent, absent or gradual. Technologically powered temporal and motile flexibility should enrich, not devalue, the freedom to be slow and still.

\section{Social Bodies in (Accelerated) Motion}

In his expansive interrogation of The Practice of Everyday Life, Michel de Certeau invokes mass transit to describe the way people arrange and experience daily systems of meaning:

In modern Athens, the vehicles of mass transportation are called metaphorai. To go to work or come home, one takes a 
'metaphor' - a bus or a train. Stories could also take this noble name: every day, they traverse and organize places; they select and link them together; they make sentences and itineraries out of them. They are spatial trajectories (De Certeau 1984:115).

De Certeau believed our daily narratives possessed innate motion; that they are in large part travel stories constituting "geographies of actions" (1984:155). We are undoubtedly creatures on the move and this mobility extends to the technologies we use to transport ourselves and our ideas. In 2009 the UN's International Telecommunications Union (ITU) revealed a world captivated by portability and connectivity; mobile phone adoption across the globe had surpassed four billion worldwide and is projected to reach six billion by 2013. A May 2011 report from China's Ministry of Industry and Information Technology logged over 900 million mobile phone users in that country (Kan 2011). The iPhone is the metaphorai of the early 21 st century.

Fluid transmission and interpretation of media and its meaning(s) is an everyday social practice for billions of humans. 'Upwardly mobile', the phrase once popularly used to describe socially successful individuals and entities, has returned in practice. But this time, 'upward' is implicit, embedded in the mobility. If one is not moving oneself or ones ideas through a network of connections, sociability, and its personal and professional rewards are at risk. Influence is being enshrined as a market. Innovators lionise porousness. 'Waterfall' institutionalism is suffering decay and an agile atomisation of commerce, content and culture is emerging as the dominant social refrain. Documenting this tilt toward insistent dynamism, socio-temporal theorists Robert Hassan and Ronald Purser note:

The goods and services that exist in the supermarket through to the data center are part of a flowing and ever-accelerating networked, globalized life where the time of the clock no longer schedules and meters our individual and collective existence in as predictable a fashion as it once did (2007: 2).

Zygmunt Bauman's liquid modernity abounds as we embrace state(s) of being validated through rapid interfacing; constructs and rituals where networked motion is a 'principal source of strength and warrant of invincibility' (2000: 15). In their analysis of cosmopolitanism, deemed a critical aspect of our modern, globalised age, Szerszynski and Urry surmise that one of its chief characteristics is "extensive mobility, in which people have the right to 'travel' corporeally, imaginatively and virtually" (2002: 470). Jonathon Sterne and Emily Raine remind us that time is a core regulator of behaviours and interactions, orchestrating individual and collective activity and shaping relations within nuanced social networks (2006). It is the pace of real-time that governs Szerszynski and Urry's extensive mobility. Andy Greenwald describes the web as an "accelerated bubble of hypertime" (2003: 277). Our daily ICT use inhabits this accelerated bubble; a culture of 'always on' and always occupied, where "messaging is instant. Overnight delivery is slow. We measure in minutes and seconds the wait for the headline news, credit-card approval, romance and wisdom" (Gleick 1999: 286). Pausing to reflect on the accelerating gap between his own media life and that of his children, New York Times journalist Brad Stone is resigned to the fact that, "My daughter and her peers will never be 'off the grid.' And they may come to expect that stores will emanate discounts as they walk by them, and that friends can be tracked down anywhere" (2010). Stone is clearly nervous, but a rapidly capable, tethered existence need not be a negative state by default. The digitally persuasive and pervasive should, however, look closely at the fringe dwellers of our technological and temporal arrangements to interrogate and (where required) equalise the meanings and value systems they are endorsing.

\section{The Published Self}

Publishing in the digital age, as Henry Jenkins has explored at length, is a trans-modal, multiplicitous event. No longer the linear journey between artefact and audience that characterised the mass, industrialised media age, in our molecularised media universe it is an intricate series of meditative and symbolic negotiations across and within temporal and contextual spaces. A growing proportion of these negotiations concern the digital presentation of the self and its relationship to digital selves; publishing is more personal than ever. A Lancaster University report to the UK Government in 2006 on Social networks and future mobilities records the transformation of "the average traveller from the quasi homo oeconomicus, myopic and individualistic, to a network actor, who tries to achieve his or her goals as part of a network of interacting and negotiating actors (Larsen, Urry and Axhausen 2006: 7). This same report notes that social networks are an 'accomplishment' of material and social mobility. Our tribes have 
always held our power, but those tribes are now forged and worn in public. Online reputation brokers are emerging to help us negotiate the 'ambient awareness' of our social identities (Thompson 2008), while our networked world acts to transform innate social cognition to a published social esteem. As our captivation with social networking deepens and distributes, Larsen, Urry and Axhausen's 'goals' become more immersive and intimate. Paul Ricoeur teaches us that "self interpretation becomes self-esteem. In return, self-esteem follows the fate of interpretation" (Ricoeur 1992: 179). We know that self-esteem is socially shaped; that self-reflection is derived by social reflection. We also know that managing our public perception is a lifelong social process, increasingly performed and administrated in digital publics (Boyd 2008). In this material and psychological landscape of networked interdependence, our reflections are hyper-visible and bound up with others. Our conversations are sacred, the spaces in which they occur privileged; their scability and pace a basis for determining personal and social worth. A successful digital citizen is travelling through a social circuit at all times - publishing and mediating multiple connectivity channels via their personal computing device(s). Physical possession of these devices still carries socially symbolic weight (Fortunati and Cianchi 2006), however status is increasingly conferred and contested in the execution of the artefact's purpose: it is what one does with one's device that counts. A mobile phone used exclusively to receive calls may serve the needs of its master and harm none, but a shifting social temperament challenges this choice as bigger picture leeching (even if it professes not to ascribe blame to the owner). In a peer-to-peer society, cohabitation and harmony (and the worth they induce) requires reciprocity at minimum, generosity as ideal. Following this line of thought, giving and doing may be invisible and insufficient if unpublished.

Communicative acceleration, spurred by technology, is elevating personal conversation in public to dominant social and cultural discourse, and deepening our reflex to share. While our self-selective publishing of informational intimacies is an act of sharing, it is also everyday surveillance, classifying our semantic and social standing in the mediated ecosystem. (Lyon 2003) When communication is social currency and our networked, digital identities are powered by published exchanges and artefacts, there is a rising pressure to be seen (surveilled) to attain and retain social worth. Offering oneself for social tracing means dynamic negotiation and engagement of the opportunities created by new technologies to articulate the self. In a dense analysis of mobile communication and cultures around the world, Manuel Castells and colleagues found "a youth culture that finds in mobile communication an adequate form of expression and reinforcement" (Castells et al 2007: 127). This reinforcement is not limited to youth cultures. For the billions equipped with mobile self-publishing portals, definition and worth is performed and distributed in the density of one's social graph, the richness of one's artefactual contributions and the throughput they may trigger. Self-identification and verification is becoming inextricable from the networked device. Ken Jordan, Jan Hauser and Steven Foster stress the importance of this issue (and its relationship to the industries of trust and reputation):

What should online "citizenship" mean in an era of $24 / 7$ connectivity to a ubiquitous information infrastructure? In this new world, you will have an online identity that remains constant, allowing for continuity between your experiences in separate online environments. As in real life, when you go from one virtual social milieu to another your identity will acquire a history. But because this will take place in a digital realm, designed by code and made of data, information will be attached to your identity in ways we are only now beginning to appreciate. Who decides what that capability will be, and most important, whether it contributes or not to civil society? What will your "persistent identity" online say about you, and what shouldn't it say? (Jordan, Hauser and Foster 2003: 2).

Primed as 'hunter-gatherers of media' (Jenkins 2009), personal broadcasting (sometimes referred to as 'lifecasting') is filling our media moments. Industry statistics from 2009 reveal that nearly 400 million individuals visited the world's most popular social publishing platform Facebook during one month, each spending an average of 20 minutes engaging with the site (Solis 2009). The popular of micro-blogging platforms like Twitter continues to boom. If Jenkins' transmodal negotiations and Hall's active encoding and decoding practices (1980) represent movement through personal and social narratives, identities and relationships, our networked society is stirring up a dervish of motion.

Charles Leadbeater tells us "the web will encourage us to see everyone as potential participants in creating collaborative solutions through largely self-organising networks" (2008: 5). Few would dispute the legion of catalysing opportunities this view introduces. But consider the unexercised potential of a network actor. The operative word in Leadbeater's vision is 'see'. We should be concerned with how this 'sight' is constituted. Where is it performed, transmitted and received? Who determines its visibility and (therefore) viability? What are the repercussions if we are not seen as a mobilising entity in the persuasive participatory paradigm? David Lyon suggests that online social networking, arguably the exemplar of public conversation in the Internet age, inverts the historical broadcast paradigm 
and transforms individual users from "passive to active, since surveillance in this context offers opportunities to take action, seek information and communicate. Online social networking therefore illustrates that surveillance - as a mutual, empowering and subjectivity building practice - is fundamentally social" (Albrechtslund 2008). Leadbeater concedes that "the web most rewards those who are already well connected by allowing them to network together, reinforcing their privilege" (Leadbeater 2008). As Clive Thompson discovered when he spoke to young adults who had "never lived without online awareness. For them, participation isn't optional. If you don't dive in, other people will define who you are. So you constantly stream your pictures, your thoughts, your relationship status and what you're doing — right now! — if only to ensure the virtual version of you is accurate, or at least the one you want to present to the world" (Thompson 2008). To be part of the network and not be publishing (reacting, refracting) invites a social and reputational void.

In a spirited debate between web 2.0 critic Andrew Keen and author David Weinberger for the Wall Street Journal online, Weinberger lauds the virtually euphoric state of philosophical and intellectual engagement the social web has afforded him (casting the pre-web era as isolated and glacial):

Ideas were scarce back then because space, time and the limitations of paper made it hard to hear what others were saying and well nigh impossible to talk with them about it. Today I am in contact with people who come up with ideas I'd never have encountered, who are sources of wide expertise, who squirrel away in public on tiny topics, who spew a long tail of speculations with occasional insights that are worth the wait... (Weinberger 2007).

Weinberger's assessment is not uncommon, nor is it entirely inaccurate. However, this sentiment is used to propel and propagate an occasionally naive causal narrative of the Internet era; wherein, if you acquiesce and share alike, you shall discover untold social and cultural riches. Dissecting these myths, Kym Thorne and Alexander Kouzmin surmise that "Constant, global, digital motion is everything" (Thorne and Kouzmin 2008: 2). Where then, lies stillness?

\section{Location, Location, Location}

Being 29,198ft above sea level is no longer an excuse for not answering. In 2007 China Telecom installed a mast near the Everest base camp (Tryhorn 2009).

Cultural geographers have shown us that space, place and time are interconnected and mutually constitutive. Throughout the history of communication technologies commentators have lauded their progressive, transcendent effect on distance. People on opposite sides of the planet could feel like they were in the same room while using the telephone. Now, they can conduct a live video chat then follow up by monitoring the other party's activities moment to moment via a life-casting application like Twitter (www.twitter.com). The magical quality conjured by early electrical wonders (Marvin 1990) is alive and well as we domesticate distance and render space immaterial. But the growing preoccupation with real-time, synchronous updates and exchange bolsters David Morley's case for the "exaggerated death of geography" (Morley 2003). Mobile technologies invite a focus on place and the moment embedded therein. How often do we start our mobile conversations by calling out our, asking and answering 'where we are' and where we are en route (Weilenmann 2003). Locally focused online communities and services are on the rise. We may have collapsed distance, but place and its circumstantial composition are becoming more, not less, important to those on the move and those monitoring our movements. Digital super-corporations like Google and Facebook have introduced much hyped, real-time, location based supplements to their services, encouraging their users to reveal more detailed geographic data, then expose that information to real-time search in the digital public. Mirroring the convergence of device and function (phones becoming mobile computing portals), the original question asked of participants on the social web - 'what are you doing' - found itself aligned to that of the mobile phone - 'where are you'? A slate of new media businesses has emerged in a short span of time to capitalise on this trend. These location based social networks require a user to 'check in' and publish their precise location to their connections (sometimes, the digital public at large). The cartographic might of Google (which is power-mapping the earth, the seas, even the solar system) and the carrying of geo-aware smart phones means that location (and superficial circumstance) is pinpointed with extreme accuracy. Some of these applications, such as Foursquare, integrate competition and reward as an addictive differentiator. If a user 'checks in' at a specific location (i.e. a popular coffee shop) with enough 
frequency, that user is anointed the virtual 'mayor' of that location. This encourages participants to embed in socially desirable and conducive locations, and creates a public badge of honour (not only are they at the hippest joint in town, they are the resident kingpin). In this scenario, real world location and situation become virtual assets, tethered to digital profile and status. If we are not claiming our location then at best, we 'miss out' on the full riches of reputational schema, and at worst, it is assumed we have something to hide. As technology journalist Pete Cashmore predicted in 2009, "Soon, our whereabouts may optionally be appended to every Tweet, blog comment, photo or video we post" (Cashmore, 2009). Our coordinates have become social currency, with the value in the reveal, not the hold. Technologists like Stowe Boyd affirm a future of socio-spatial primacy: "The innate capability we have to shift in a heartbeat from a given public, and our corresponding persona, to another, is now being accelerated by streaming social tools. This will be the decade when publicy displaces privacy, online and off” (Boyd 2010).

The fettishisation of real-time and location (as a sacred marriage of context) is compounded by an appetite for user-generated content in news and commerce. We are no longer the principal stakeholder in our "networked nature of impressions" (Boyd, 2006) While advocates justly hail the equalising impact of 'real stories and real reporting from real people' (as opposed to a clinically polished, filtered company line, beholden to special interest), the demand for amateur multimedia narratives (with its tantalising promise of recognition and reputation) applies ever greater pressure to connect, embed and broadcast in the moment. Companies need consumers to co-create, shape and market their wares and will put up rewards for doing so. News organisations need non-professional content to understand trends, lure audiences and diffuse the rising costs of an unsustainable business model. As journalist and citizen media activist Dan Gilmor sees it, thanks to new media mobilities, ordinary people write the first draft of history' in a way that can be amplified and committed to record (Gilmor 2006). This produces a melting pot of micro and macro pressures to participate and publish in situ. Our personal social network expect to keep up with our movements; present and potential employers expect to see that we are viable, richly connected entities, on the move; the market insists it can serve us better if it knows more about who, when and where we are; and the newsmakers expect and encourage us to play a larger role in their historically privileged territories by virtue of our mobility. As 'wiki-nomics' champions Don Tapscott and Anthony Williams see it, "Every individual now has a role to play in the economy, and every company has a choice - commoditize or get connected" (Tapscott and Williams 2006: 31). There are exciting possibilities imbued in the arrival of the real-time, networked web, including the promise of vivid behavioural mapping and an enlightening zeitgeist that will teach us about ourselves. There will also likely be fascinating applications for scholars and researchers - as the subject of phenomenological investigation and as ethnographic tools in and of themselves. But as we chart and colonise the spaces in between our media moments, mapping and publishing our motion as we live and experience it, what happens if we press pause?

\section{Can Silence Keep Up?}

In his rhythmanalysis, Henri Lefebvre posits that "everywhere where there is interaction between a place, a time and an expenditure of energy, there is rhythm" (Lefebvre 1992: 15). Our networked society is defined by these rhythms. Theorists like Paul Virilio have argued that these technologically facilitated rhythms are speeding up, meaning "the time allotted to decision-making is now insufficient" (Virilio 2000: 92). When we can be relied on for reach and response in all places, at all times, what does it mean if we cannot, or do not, immediately talk back? Mobile technologies have been praised for letting us make the most of our time. The 'dead air' that existed when we travelled to and from moments and locations can now be populated with mediated, meaningful exchange. Yet, when motion and output is the predominant operative state, delay becomes inoperative. The risk here is that we confuse nonvisible motion with stasis or ossificiation; a value judgement that ignores the motion of our inner life and mechanises us as network nodes in a macro-social web. If we are not in motion, we are broken. Repose or reflection is invisible and therefore unviable.

Our suite of silences - meditation, pause, listening and repose - serves important purposes in everyday life. It is in our downtime that we recharge, recalibrate and reflect. If we stop moving we can better survey our surrounds and our state(s); better respond to them. Put simply, as human beings, every now and then we need to take a breath, do nothing, or have a think. As Adam Jarworski affirms, "Silence is a unifying concept for tackling diverse communicative phenomena: linguistic, discoursal, literary, social, cultural, spiritual and meta-communicative" (Jaworksi 1997: 3). It is also an ageless metaphor for communication itself- a pregnant space, illuminating via its 
darkness. Oral historians champion the innate value of silence as a 'non-message' compelling closer examination. Online community managers and strategists understand the demography of lurkers is laden with critical 'tells' (Preece and Nonnecke, 2003; Preece, Nonnecke and Andrews 2004). Silences and qualitatively 'silent' states can be dense sites of meaning and consequence. Yet silence in the digital age is undergoing a conceptual devaluation. The regular production of conversationally 'sticky' content is privileged as both socio-lubricant and characteristic of a worthy 21 st century citizen. Publishing a trail of personally curated identity markers to enable discovery and social traction is framed as a "public good" (Joinson 2008: 2). In a geo-sensitive ecosystem that demands our engagement to function and thrive, downtime becomes unproductive to the collective, absence a handicap to be treated. Our reputations and our communities reject dead air. What then of those who cannot - or will not - testify motion through expression and self-surveillance?

The social web and mobile interfacing devices have created a "proliferation of places, technologies, and 'gates' that enhance the mobilities of some while reinforcing the immobilities of others" (Sheller and Urry 2006: 213). As Nicola Green explains:

The connection between mobile space and time, as articulated in multiple, heterogeneous places and rhythms, is not constant and does not have equal effects for all. Access to and control of time and mobility are always shaped by the context of situated social practice, as collectively created and maintained by a number of different individuals and social groups. In asking who benefits from these heterogeneous causes and effects, we are asking questions about the power geometries of mobile time (Green 2002: 291).

Disconnection and non-participation can be an act of dissent. A choice not to watch, post or download can constitute resistance (to the content itself, to the system it is contained within, or the audience it is intended for). Although this is still the case with newer media and platforms, there is a paradox looming. As self-profiling and propagation within digital commons becomes a successively larger part of our lives, non-presence is denied symbolic resonance because it of its inherent invisibility. In a real-time, location powered commons, absence is an ontological issue. The participatory paradigm is 'lean forward' versus 'lean back', “requiring more focused, concentrated, active attention" (Mackay 2005: 139). Watching television or reading a newspaper does not demand visibility or expansive social network reach. Consider journalist Howard Jacobsen's return to the 'slow browse' for The Guardian. Withholding ICTs for a week as an experiment in 'disrupted subservience', he switches off Google and heads to a library to serve his informational needs. After adjusting to a jarring difference in pace and expectation, he finds the experience is imbued with an ecstasy of potential:

A library is to the internet what the telly of yesterday is to telly now - a palace of serendipities, where no limits are set to your curiosity, no assumptions made about your ignorance, a true democracy of the intelligence (Jacobson 2002).

Jacobson may be guilty of nostalgia, but his field test raises an important point. In the absence of our social stop-watch (in the silence of a public space that, in this instance, privileges silence) we can write our own rules and set our own pace. We can (re)claim space and time for ponderance and repose. David Levy argues this is a contemporary cultural imperative:

...our more-faster-better attitude, which is intimately connected with the striving for technological advance, is driving out slower practices that are essential to our ability to govern ourselves with maturity. Without adequate time to think and reflect, time to listen, and time to cultivate our humanity, and without spaces that are protected from the constant intrusion of information and noise, I do not see how we can respond to the innumerable social and political challenges of the new millennium with the quality of attention they deserve (Levy 2006: 1).

As we concern ourselves with the rituals of mediated, cumulative and traceable social engagement, we should not neglect the cultural value of the silence and the slow. For authentic community building is a slow boil activity and quality is not interchangeable with amplification.

\section{Swimming Like Sharks}

Real travellers regularly take time to stop moving and to think instead. They occasionally consider, register, and eliminate impressions received. And of course, real travellers have a purpose and, above all, homes. If not, they 
are drifters. And isn't modern communication society creating exactly that: drifters in a universe of sense (Burgelman 2000: 9).

Questions and concerns about human movement, speed and interaction in everyday life are as old as humanity. As Giuseppina Pellegrino observes, "history can be read through change, movement and displacement of people, objects and, increasingly, information, to the extent of considering modernity itself - and its globalizing face - as the product of flows, fluxes and changing landscapes" (Pellegrino 2007: 59). Stowe Boyd points to a long line of philosophers who have argued we are menaced by a 'poverty of attention', including Diderot as early as 1755 (Boyd, 2010). It is easy to neglect history when considering the relationship between speed and information. There is no need to panic, or condemn. Technology is not the death of us. But as the high priests of the social web evangelise a new era of interconnectedness, we must be careful not to exchange one flawed gate keeping model for another. A burgeoning emphasis on digital embeddedness as reputational worth and a pre-requisite for new millennial citizenship threatens to create a wilderness of detachment; an ecosystem whose inhabitants and (in)actions are off the informational radar, therefore diminished in capital and worth. Can this silent jungle imprint on an era characterised by performative exchanges in relentless motion?

According to Virilio, "The speed of light does not merely transform the world. It becomes the world" (Virilio 2000). If our connective metaphori carry, project and reflect us through a 'culture of flow' (Wilken 2009) at light speed, new lines of inquiry will become necessary to deal with the impact of selective (or imposed) non-presence. As we live our lives in real time publics, we will need to consider whether there is a real time private as well as public, if there is an unreal time, and how both are valued by popular and powerful systems of order. Silence and slowness are unlikely to evaporate. People will continue to smell roses, rest their eyes and hide under covers. Some will deftly reinvent repose, meditation and incubation within a new mediascape (call it mindfulness 2.0). But if we canonise relentless, participation via published artefact and trace signals without rewarding the slow and the analogue, we risk institutionalising a different digital divide - a zone of silence - where the unpublished self is politically cast in opposition to the quantified (Winner 1986). The ephemerality of the digital commons and its collective memory means asking these questions is even more important (Pietrzyk 2010; Frost 2003). If a social networking status update or a blog post conflates too intensively with worth and esteem, what happens when these social artefacts dissolve from our screens? As belonging is constituted in vivace, panoptical chambers we need to affirm nonpeformative, silent belonging, as meaningful, memorable and viable.

\section{References}

Albrechtslund, A. (2008) 'Online Social Networking as Participatory Surveillance', First Monday, Volume 13, Number 3, March 2008, http://firstmonday.org/htbin/cgiwrap/bin/ojs/ index.php/fm/article/viewArticle/2142/1949

Arminen, I., \& Weilenmann, A., (2009) 'Mobile presence and intimacy - reshaping social actions in mobile contextual configuration', Journal of Pragmatics, Volume 41, Issue 10, October 2009, Special Issue on Communicating Place, Space and Mobility, pp. 1905-1923

Boyd, D. (2006) 'Friends, Friendsters, and Fop 8: Writing community into being on social network sites', First Monday, Volume 11, Number 12 - 4 December 2006 http://www. uic.edu/htbin/cgiwrap/bin/ojs/index.php/fm/article/ viewArticle/1418/1336

Boyd, D. (2008) 'Why Youth Social Network Sites: The Role of Networked Publics in Teenage Social Life', Youth, Identity, and Digital Media, Ed. David Buckingham, John D. and Catherine T. MacArthur Foundation Series on Digital Media and Learning, Cambridge, MIT Press.
Boyd, S. (2010) 'The Decade Of Publicy', www.stoweboyd.com, http://www.stoweboyd.com/message/2010/01/the-decade-of-publicy.html

Boyd, S. (2010) 'The False Question Of Attention Economics', www.stoweboyd.com, http://www.stoweboyd.com/ message $/ 2010 / 01 /$ the-false-question-of-attention-economics.html

Burgelman, J. (2000) 'Traveling with Communication Technologies in Space, Time, and Everyday Life: An Exploration of Their Impact', First Monday, Volume 5, Number 3 (March 2000), http://firstmonday.org/htbin/ cgiwrap/bin/ojs/index.php/fm/article/view/733/642

Cashmore, P. (2009) '10 Web trends to watch in 2010', cnn.com http://edition.cnn.com/2009/TECH/12/03/cashmore.web. trends.2010/index.html

Cassells. M., (2007) Mobile Communication and Society: A global perspective, MIT Press 
DeCerteau, M. (1984) The Practice of Everyday Life: 115-116

Fortunati L. \& Cianchi, A., (2006) 'Fashion and technology in the presentation of the self', Mobile Communication in Everyday Life - Ethnographic Views, Observations and Reflection, Joachim R. Höflich, Maren Hartmann (Eds.) Frank \& Timme

Frost, C. (2003) 'How Prometheus is Bound: Applying the Innis Method of Communications Analysis to the Internet,' Canadian Journal of Communication 28(1): 9-24

Gleick, J. (1999) Faster: The Acceleration of Just About Everything, Random House

Gilmor, D. (2006) We the Media: Grassroots Journalism by the People, for the People, O’Reilly Media

Green, N. (2002), On the Move: Technology, Mobility, and the Mediation of Social Time and Space, University of Surrey, The Information Society, 18:281-292

Greenwald, A. (2003) Nothing Feels Good: Punk Rock, Teenagers and Emo, New York: St Martin's Griffin

Hassan, R. \& Purser, R.E. (2007) 24/7: time and temporality in the network society, Stanford University Press

Ito, M., Okabe, D. \& Matsuda, M. (Eds.), (2005) Personal, portable, pedestrian: Mobile phones in Japanese life. MIT, Cambridge

Jacobsen, H. (2002) 'Life off line: Howard Jacobsen spends a week without his mobile, fax and email', The Guardian

Jenkins, H. (2009) Keynote: Revenge of the Origami Unicorn: Five Key Principles of Transmedia Entertainment, (http:// techtv.mit.edu/collections/convergenceculture:847/videos/4720-keynote-revenge-of-the-origami-unicorn-five-key-principles-of-transmedia-entertainment)

Joinson, A. (2008) 'Looking at', 'Looking up' or 'Keeping up with' People? Motives and Uses of Facebook, University of Bath, UK. Proceeding of the twenty-sixth annual SIGCHI conference on Human factors in computing systems, Florence, 2008

Jordan, K., Hauser, J. \& Foster, S. (2003) 'The Augmented Social Network: Building identity and trust into the next-generation Internet', First Monday, Volume 8, Number 8,

(http://firstmonday.org/issues/issue8_8/jordan/index.html)

Kan, M. (2011) 'China Reaches 900 Million Mobile Phone Users', PC World, May 25, 2011, (http://www.pcworld.com/businesscenter/article/228611/china_reaches_900_million_mobile_ phone_users.html)

Larsen, J., Urry, J. \& Axhausen, K. (2006) Social networks and future mobilities, (https://www.ivt.ethz.ch/vpl/publications/ reports/index/edit/ab330.pdf)

Leadbeater, C. (2008) We Think, Profile, (http://www.charlesleadbeater.net/cms/xstandard/ChapterOne.pdf)

Lefebvre, H., (1992), Rhythmanalysis: space, time and everyday life, Translated edition (2004), Continuum
Levy, D. (2006) More, Faster, Better: Governance in an Age of Overload, Busyness, and Speed, First Monday, Special Issue \#7: Command Lines: The Emergence of Governance in Global Cyberspace, (http://firstmonday.org/htbin/cgiwrap/bin/ojs/ index.php/fm/article/view/1618/1533)

Licoppe, C. (2004) 'Connected' presence: the emergence of a new repertoire for managing social relationships in a changing communication technoscape. Environment and Planning D: Society and Space 22 (1), 135-156

Lyon D. (2003) Surveillance as social sorting: privacy, risk, and digital discrimination, Routledge

Mackay, H. (2005) 'New connections, familiar settings: issues in the ethnographic study of new media use at home', In: Hine, Christine ed. Virtual Methods: Issues in Social Research on the Internet. Oxford, UK, Berg: 129-140

Morley, D. (2003) 'What's "Home" Got to Do with It?: Contradictory Dynamics in the Domestication of Technology and the Dislocation of Domesticity', European Journal of Cultural Studies 6.4

Preece, J., Nonnecke, B., 'Silent Participants: Getting to Know Lurkers Better', in Fisher, D., Lueg, C. (2003) From Usenet to CoWebs: interacting with social information spaces. Springer

Preece, J., Nonnecke, B., Andrews, D. (2004) 'The top 5 reasons for lurking: Improving community experiences for everyone,' Computers in Human Behavior, 2, 1

Pellegrino, G. (2007) 'Discourses on Mobility and Technological Mediation: The Texture of Ubiquitous Interaction', PsychNology Journal, Volume 5, Number 1:59-81

Pietrzyk, K. (2010) "Activism in the Fast Lane: Social Movements and the Neglect of Time", Fast Capitalism Volume 7 Number 1,2010

Poster, M. (1990) The mode of information: Poststructuralism and social context, Chicago: University of Chicago Press

Potter, A.B. (2006) 'Zones of silence: A framework beyond the digital divide', First Monday, Volume 11, Number 5, May 2006, (http://firstmonday.org/htbin/cgiwrap/bin/ojs/index. $\mathrm{php} / \mathrm{fm} / \mathrm{rt} /$ printerFriendly/1327/1247)

Ricoeur, P (1992) Oneself as another, University of Chicago Press

Sheller, M. \& Urry, J. (2006) 'The new mobilities paradigm', Environment and Planning A, Volume 38, pp. 207-226

Sterne, J. \& Raine, E. (2006) 'Command tones: Digitization and sounded time’, First Monday, Special Issue \#7: Command Lines: The Emergence of Governance in Global Cyberspace, (http://firstmonday.org/htbin/cgiwrap/bin/ojs/index.php/ $\mathrm{fm} /$ article/view/1607/1522)

Stone, B. (2010) 'The Children of Cyberspace: Old Fogies by Their 20', New York Times, January 9, 2010 (http:// www.nytimes.com/2010/01/10/weekinreview/10stone. $\mathrm{html}$ ?src $=\mathrm{tpt}$ ) 
Solis, B. (2009) 'Revealing the people defining social networks', October 2009 blog post, www.brainsolis.com (http://www.briansolis.com/2009/10/ revealing-the-people-defining-social-networks/)

Szerszynski, B. \& Urry, J. (2002), 'Cultures of cosmopolitanism', The Sociological Review: 462-481 (http://www.lancs.ac.uk/ fass/centres/csec/docs/szerszynski_cultures_of_cosmopolitanism.pdf)

Szerszynski, B. \& Urry, J. (2006) 'Visuality, mobility and the cosmopolitan: inhabiting the world from afar', British Journal of Sociology, Volume 57,Number 1: 113-131, (http://www. promusica.se/Library/Electronic\%20texts/Szerszynski_ urry2006.pdf)

Tajfel, H. (1981) Human Groups and Social Categories, Cambridge: Cambridge University Press

Tapscott, D. \& Williams, A. (2006) Wikinomics: How Mass Collaboration Changes Everything, New York: Portfolio

Thompson, C. (2008) 'Brave New World of Digital Intimacy', September 5, 2008, New York Times

Thorne K. \& Kouzmin, A. (2008) 'Cyberpunk-Web 1.0 "egoism” greets group-web 2.0 "narcissism": Convergence, consumption, and surveillance, in the digital divide', Administrative Theory \& Praxis, Volume. 30, Number.3, September 2008 (http:// unpan1.un.org/intradoc/groups/public/documents/UNPAN/ UNPAN031490.pdf)
Tryhorn, C. (2009) 'Nice talking to you ... mobile phone use passes milestone', www.guardian.co.uk, Tuesday 3 March, 2009 (http://www.guardian.co.uk/technology/2009/mar/03/ mobile-phones 1)

Virilo, P. (2000) Landscape of Events, MIT Press

Virilo, P. (2000) Ctheory Interview With Paul Virilio: 'The Kosovo War Took Place In Orbital Space', Ctheory.net (http://www.ctheory.net/articles.aspx?id=132)

Weilenmann, A. (2003) '“I can't talk now, I'm in a fitting room”: Formulating availability and location in mobile phone conversations', Environment and Planning A, Volume 35:1589 - 1605, Special Issue on Technology and Mobility, Ed. E. Laurier.

Weinberger, D. (2007) Reply All - debate on Web 2.0 between authors Andrew Keen and David Weinberger, July 182007 (http://online.wsj.com/article/SB118460229729267677. html)

Wilken, R. (2009) From Stabilitas Loci to Mobilitas Loci: Networked Mobility and the Transformation of Place, Fibreculture Issue 6 - mobility, new social intensities and the coordinates of digital networks (http://journal.fibreculture. org/issue6/issue6_wilken.html)

Winner, L. (1986) 'Do artifacts have politics?' in The Whale and the Reactor: a Search for Limits in an Age of High Technology, University of Chicago Press 
